\title{
Significados produzidos por futuros professores de Matemática ao estudar diferentes modelos geométricos
}

\author{
Meanings produced by future mathematics teachers when studying different \\ geometric models
}

\author{
Clovis Lisbôa dos Santos Junior ${ }^{1}$ \\ Lícia de Souza Leão Maia
}

\begin{abstract}
Resumo
Recorrente nas discussões científicas acadêmicas e, consequentemente, nas investigações da área em Educação Matemática, o estudo de Geometrias não Euclidianas na formação inicial do professor de Matemática pode ampliar a compreensão dos licenciandos acerca de conceitos geométricos euclidianos. No presente artigo, apresentam-se os resultados de uma Atividade de Ensino aplicada a futuros professores de Matemática, com o objetivo de analisar a produção de significados dos participantes no estudo de conceitos geométricos não euclidianos. A Teoria Histórico-Cultural de Vygotsky, complementada pela Teoria da Atividade de Leontiev e pela Atividade Orientadora de Ensino de Moura são os aportes teóricos que subsidiaram a investigação e as ações pedagógicas neste estudo. Ao aceitarem a existência de outros modelos geométricos, os licenciandos investigados modificaram a maneira como se relacionam com o espaço em que vivem e, assim, desenvolvem maior autonomia no processo de construção dos conceitos atribuindo significados diferenciados para os objetos geométricos estudados.
\end{abstract}

Palavras-chave: Educação Matemática; Atividade Orientadora de Ensino; Formação de professores; Geometrias não Euclidianas.

\begin{abstract}
Recurring in academic scientific discussions and, consequently, in investigations in the area of Mathematics Education, the study of non-Euclidean geometries in the initial formation of the mathematics teacher can increase the undergraduate students' understanding of Euclidean geometric concepts. In the present article, the results of a Teaching Activity applied to future mathematics teachers presented, with the aim of analyzing the production of meanings of the participants in the study of non-Euclidean geometric concepts. Vygotsky's Historical-Cultural Theory, complemented by Leontiev's Activity Theory and Moura's Teaching Guidance Activity, are the theoretical contributions that supported the investigation and pedagogical actions in this study. By accepting the existence of other geometric models, the undergraduate students investigated changed the way they relate to the space in which they live and, thus, develop greater autonomy in the process of constructing the concepts by assigning different meanings to the studied geometric objects.
\end{abstract}

Submetido em: 12/10/2020 - Aceito em: 01/02/2021 - Publicado em: 01/06/2021

${ }^{1}$ Doutor em Educação Matemática e Tecnológica pela Universidade Federal de Pernambuco - UFPE. Professor da Universidade do Estado da Bahia - UNEB/Campus X, Brasil. E-mail: prof.clovislisboa@gmail.com. ORCID: https://orcid.org/0000-0003-1693-4484

${ }^{2}$ Doutora em Sciences de L'éducation - Université de Paris V (Sorbone). Professora do Programa de Pós Graduação em Educação Matemática e Tecnológica da Universidade Federal de Pernambuco - UFPE, Brasil. Email: liciaslm@hotmail.com. ORCID: https://orcid.org/0000-0002-9525-3777 
DOI: $10.20396 /$ zet.v29i00.8661597

Keywords: Mathematical Education; Teaching Guidance Activity; Teacher training; Non-Euclidean Geometries.

\section{Introdução}

A matemática construída pela sociedade foi utilizada para explicar, compreender e solucionar problemas do cotidiano das pessoas em diferentes culturas, em distintos momentos históricos. Dentre os campos de pesquisas da Matemática que oferecem um modelo para análise do espaço físico, o da Geometria Euclidiana foi utilizado durante séculos como a principal área do conhecimento humano para denotar o espaço e suas propriedades. No entanto, será a Geometria Euclidiana o único modelo geométrico capaz de analisar o nosso espaço físico terrestre?

A partir desse questionamento, a proposta deste estudo é refletida no interesse pela história de fatos ligados às construções do conhecimento geométrico euclidiano e suas limitações, na possibilidade de aprofundamento dos estudos sobre as métricas não euclidianas e, em particular, no alinhamento acerca do estudo dessas Geometrias na formação inicial de professores de Matemática.

Assim, o presente trabalho busca tecer reflexões acerca dos desafios relacionados ao desenvolvimento do conhecimento geométrico a partir da análise de significados produzidos por futuros professores de Matemática sobre o estudo de Geometrias não Euclidianas. Para tanto, os pressupostos teórico-metodológicos da Atividade Orientadora de Ensino proposta por Moura $(1996,2001)$ foram considerados como contexto para a negociação de significados entre os participantes da pesquisa. A análise da produção de significados foi realizada com base nos aportes teóricos da Teoria Histórico-Cultural, que tem como expoente Vygotsky (1987), e na Teoria da Atividade de Leontiev (1978).

\section{Alguns pressupostos teóricos}

\section{Perspectiva Histórico-Cultural e Seus Desdobramentos}

A ideia central da Teoria Histórico-Cultural (doravante, THC) proposta por Vygotsky nos orienta que o desenvolvimento das funções psíquicas superiores se dá na interação social e por intermédio do uso de signos. Nessa perspectiva, o âmago do desenvolvimento cognitivo está relacionado à "internalização dos mediadores culturais, ou seja, à transformação do cultural em psicológico" [ênfase no original] (Abreu, 2000, p. 108).

Para Castorina (1996), quaisquer transformações no plano interpsicológico provocam transformações no plano intrapsicológico, desconsiderando nesse processo a mera "transmissão" de um plano para o outro, mas valorizando, sim, uma "transformação". Assim, o sujeito internaliza por meio de interações sociais que, ao constatá-las, ele delas se apropria, recria-as e incorpora-as às suas estruturas. A construção de significados feita pelo sujeito transforma-o e, consequentemente, transforma a realidade. 
Na visão de Vygotsky, toda função intrapsicológica é uma construção histórico-social que se manifesta a partir de uma função interpsicológica, ou seja, toda passagem do plano externo para o plano interno no indivíduo é mediada por um sistema simbólico que produz significações para as suas vivências e serve como estímulo para orientar a sua forma de sentir, pensar e agir.

Nas investigações sobre o desenvolvimento do psiquismo humano, a formação de conceitos é defendida por Vygotsky e colaboradores como uma extensão do processo de internalização e, consequentemente, da apropriação de um conhecimento. Em outras palavras, a construção de conceitos é, por excelência, uma atividade mediada por signos, que ocorre no campo cognitivo do indivíduo, com a finalidade de dirigir e controlar as ações dele próprio, criando novas formas e processos de representação dos objetos da realidade.

Outro aspecto relevante na THC diz respeito aos conceitos espontâneos e aos conceitos científicos: os primeiros são aqueles que o indivíduo aprende em seu cotidiano, originados de experiências com determinados objetos, fatos, fenômenos etc. Já os conceitos científicos são sistematizados e transmitidos intencionalmente, a partir de uma metodologia própria. Portanto, reconhecemos o papel social da escola de viabilizar a formação de conceitos científicos nos indivíduos, para que se insiram em práticas de produção de bens e serviços necessários para o desenvolvimento social, político, econômico e tecnológico da sociedade.

Para Moysés (1997), a existência de um conceito científico está sempre atrelada a um sistema hierarquizado do qual ele faz parte; e, consequentemente, cabe ao professor mediar o processo de construção desse tipo de conceito pelo educando, de modo a "estabelecer um enlace indireto entre o estudante e o objeto por meio das abstrações em torno das suas propriedades e da compreensão das relações que ele mantém com um conhecimento mais amplo" (p. 35). Assim, a formação de um conceito científico só se estabelece por meio de uma ação intencional e sistematizada, que possibilita ao sujeito uma relação consciente e consentida com o objeto do saber em jogo.

Em suma, o processo de relacionar as experiências dos educandos (conceitos espontâneos) com os conhecimentos historicamente sistematizados e referendados nas práticas humanas (conceitos científicos) exige que o agente mediador (professor) a compreenda os diferentes significados desses conceitos para os educandos. É por meio da organização adequada do ensino que o professor pode perceber em quais contextos surgem tais conceitos e em quais sentidos eles estão sendo empregados (Moysés, 1997).

Para Vygotsky (1993), a essência da formação de conceitos se constitui nas relações estabelecidas entre os sujeitos e os objetos dentro de um contexto histórico-cultural que lhes atribui significados, isto é, os conceitos se materializam em um processo de desenvolvimento histórico, por meio de uma ação compartilhada entre os sujeitos, adquirindo, em determinado contexto, um sentido próprio e pessoal para cada indivíduo. 
Como percebemos, compreender o desenvolvimento das funções psíquicas superiores é o objeto de estudo da THC, e, para realizar esse estudo, Vygotsky buscou esclarecer como se dá a produção de significados e sentidos pelos sujeitos, a fim de tratar das relações entre linguagem e pensamento. Dessa maneira, a formação de conceitos está intrinsecamente ligada à evolução do pensamento e da linguagem, pois é na conexão entre eles que um modifica e desenvolve o outro (Vygotsky, 1987).

Vygotsky (2003) afirma ainda que não existe pensamento sem linguagem: “o momento de maior significado no curso do desenvolvimento intelectual, que dá origem às formas puramente humanas de inteligência prática e abstrata, acontece quando a fala e a atividade prática, então duas linhas completamente independentes de desenvolvimento, convergem" (p.33).

Nos dizeres de Vygotsky, o pensamento não pode ser encontrado diretamente na palavra, porém ele se realiza ou se finda nela. A relação entre pensamento e linguagem é um movimento de mão dupla, em que um transforma e desenvolve a outra no decorrer do próprio desenvolvimento histórico do homem. Assim, devemos compreender que a materialização do pensamento por intermédio da linguagem exige a busca exaustiva pela captação do sistema de relações que produziu um significado compartilhado por diferentes sujeitos, até a investigação da forma como este foi empregado, o contexto em que surgiu, produzindo sentido todo próprio e pessoal para cada um (Vygotsky, 1993).

Para Vygotsky (2010), o sentido se torna uma atividade humana consciente, que surge na operacionalização da significação, em um processo histórico e cultural em busca da produção de conceitos, uma vez que

o sentido de uma palavra é a soma de todos os fatos psicológicos que ela desperta em nossa consciência. Assim, o sentido é sempre uma formação dinâmica, fluida, complexa, que tem várias zonas de estabilidade variada. O significado é apenas uma dessas zonas do sentido que a palavra adquire no contexto de algum discurso e, ademais, uma zona mais estável, uniforme e exata. (p. 465).

Dessa maneira, a diretriz da obra de Vygotsky nos orienta que o pensamento conceitual se dá por meio de significados socialmente compartilhados e não apenas reproduzidos no processo de transição construtiva que se estrutura a partir do diálogo entre as dimensões sociais, interpessoais, e individuais intrapessoais. Ao compartilhar significados, o sujeito constrói seus próprios referenciais, o que chamamos de "sentidos".

O papel do professor como mediador do processo de ensino e aprendizagem exige que ele busque conhecer o alcance dos significados e sentidos atribuídos pelos discentes às suas falas, uma vez que, "dependendo do contexto uma palavra pode significar mais, ou menos, do que significaria se considerada isoladamente: mais, porque adquire um novo conteúdo; menos, porque o contexto limita e restringe o seu significado" (Vygotsky, 1987, p. 125).

Desse modo, no desenvolvimento das funções psíquicas superiores, o significado de cada palavra é uma generalização, um conceito. Cabe ao professor organizar adequadamente as atividades voltadas para o ensino e estar sempre atento durante o processo de 
DOI: $10.20396 /$ zet.v29i00.8661597

compartilhamento de significados, à possibilidade de haver, nas relações estabelecidas entre docente e discente e entre os próprios estudantes, equívocos, distorções e outros problemas que podem ser encarados como obstáculos didáticos no processo de aprendizagem.

Teoria da Atividade: conceitos e perspectivas

Leontiev, a partir dos pressupostos da THC, ocupou-se em estudar a atividade mental e a sua relação com o próprio desenvolvimento da personalidade do homem (Moysés, 1997). Os estudos desenvolvidos deram um significado mais aprofundado ao termo "atividade", propondo a atividade como um processo humano psicologicamente caracterizado com o fim de satisfazer uma necessidade, distinto de uma simples ação. O sentido atribuído a esse termo inspirou a gênese da teoria de Leontiev (1978), que a designou de Teoria da Atividade.

Ele aprofundou o conceito de atividade e transpôs a visão central de uma ação mediada para um processo de desenvolvimento coletivo, em que a função articulada por indivíduos se torna um modo de organização de cada sujeito, e a ação interpsíquica vai se transformando em ação intrapsíquica (Moysés, 1997). Portanto, surgiu a segunda geração da Teoria da Atividade (doravante, TA), tendo Leontiev como seu principal representante.

De acordo com Braida (2012), Leontiev trouxe contribuições importantes para o conceito de atividade e centralizou seu foco na inter-relação complexa entre o sujeito individual e sua comunidade. Assim, o modelo proposto por Vygotsky não foi ampliado para um sistema de atividade coletiva, mas adaptado, de tal forma que o foco de um sistema de atividade humana não se concentra somente no nível micro, referente ao sujeito individual e aos instrumentos que opera, mas possibilita também realizar análises no nível macro, coletivo e vinculado à comunidade.

Dessa maneira, Leontiev (1978), no contexto da TA, define atividade da seguinte forma:

aqueles processos que, realizando as relações do homem com o mundo, satisfazem uma necessidade especial correspondente a ele.... Por atividade, designamos os processos psicologicamente caracterizados por aquilo a que o processo, como um todo, se dirige (seu objeto), coincidindo sempre com o objeto que estimula o sujeito a executar esta atividade, isto é, o motivo. (p. 68)

Leontiev (1978) se apropria dos estudos de Vygotsky e pondera que a atividade do homem é um processo de mão dupla entre os extremos, sujeito e objeto, onde se manifestam os movimentos recíprocos, seja este um objeto material ou simbólico. Dessa forma, o autor pontua o aspecto objetivo da atividade, ressaltando a qualidade de ser sempre, e necessariamente, orientada por um objeto.

Para Leontiev (1978), "atividade” designa os processos que, efetivando as relações do homem com o mundo, satisfazem uma necessidade especial daquele, ou seja, seu motivo; e outros processos que não atendem a esse pressuposto são por ele denominados de "ações" e “operações". A esse respeito, Kozulin (2004) esclarece que Leontiev sugere que a atividade corresponde a um motivo; a ação, a um objetivo; e a operação depende de condições. 
Os elementos estruturantes da atividade humana são fundamentais para compreendermos as relações entre significado e sentido como componentes estruturais da consciência, a qual orienta a atividade no mesmo momento em que é por ela regulada e determinada (Leontiev, 1978). O autor debruça-se sobre dois importantes conceitos, em seus estudos na perspectiva histórico-cultural de Vygotsky: significado e sentido; e proporciona um novo olhar para tais termos, expõe novas sutilezas em relação a eles e denomina-os de "significação social"3 e "sentido pessoal".

O esboço deste estudo tem como cenário a formação inicial do professor de Matemática e pretende, a partir da TA, encontrar bases teóricas e metodológicas que favoreçam analisar a produção de significados sobre o estudo de Geometrias não Euclidianas por licenciandos do curso de Matemática. E, para realizar esse estudo, utilizamos os termos "significado social" e "sentido pessoal" na acepção de Leontiev (1983). O autor considera que o ser humano, a partir das atividades que realiza, se vê imerso em um mundo de significações, as quais traduzem e apresentam as normas, os conhecimentos à cultura de uma determinada sociedade, dando-lhes sentido pessoal.

Leontiev (1978) propõe como definição para o conceito de significação social:

A significação é a generalização da realidade que é cristalizada e fixada num vector sensível, ordinariamente a palavra ou a locução. É a forma ideal, espiritual da cristalização da experiência e das práticas sociais da humanidade. A significação pertence, portanto, antes de mais, ao mundo dos fenômenos objetivamente históricos. (p.94)

Em outras palavras, as significações sociais devem ser compreendidas como a generalização da realidade por meio das práticas sociais conjuntas, a forma ideal da existência humana, imersa num mundo objetivamente histórico e cultural.

Asbahr (2014) entende que o processo de significação social se constitui como fenômeno da consciência individual, com a finalidade de produzir, dentro de sua subjetividade, o conteúdo social. A forma como o sujeito se apropria ou não de determinadas significações depende exclusivamente do sentido pessoal por ele apreendido.

Segundo Leontiev (1978), o sentido pessoal é produzido de forma subjetiva pelo sujeito e resulta objetivamente do vínculo entre o motivo da realização da atividade, aquilo que move a ação, e seu objetivo imediato, o que a orienta ao seu fim. Dessa forma, segundo Duarte (2004), a consciência humana estrutura-se e funciona com base nas relações entre significado e sentido, uma vez que a atividade humana é realizada por meio da relação mediada psiquicamente entre o seu motivo, o conteúdo de cada ação que a compõe, ou seja, significado da ação, e seu objetivo final.

Nessa perspectiva, Duarte (2004) aponta que a educação escolar contemporânea tem como um dos grandes desafios viabilizar que a aprendizagem dos conteúdos escolares proporcione determinado sentido para os estudantes. O ensino como principal atividade do

\footnotetext{
${ }^{3}$ Nesta pesquisa, os termos "significado social" e "significação social" serão utilizados para expressar o mesmo conceito.
} 
professor deve ser organizado, intencional e sistematizado, de modo a desencadear nos discentes a necessidade de apropriação do conhecimento científico, num processo que outorgue sentido pessoal à atividade de estudo, para o estudante; e de ensino, para o professor.

Dessa forma, justifica-se a pretensão desta pesquisa de analisar a produção de significados de futuros professores de Matemática acerca do estudo de Geometrias não Euclidianas na graduação, a fim de formalizar, pela exploração e pela vivência de Atividade de Ensino, conceitos científicos que possam ampliar os conhecimentos no campo da Geometria, a ponto de estabelecer sentido pessoal para a inserção desses modos de compreender os diferentes modelos geométricos nas aulas de Matemática.

Na próxima seção, como desdobramento da THC e TA, discutiremos as contribuições teórico-metodológicas da Atividade Orientadora de Ensino para o desenvolvimento de conceitos matemáticos e, consequentemente, para a formação inicial do professor de Matemática.

\section{Atividade Orientadora de Ensino: um contexto para a negociação de significados}

Os estudos realizados até o presente momento sobre a THC e a TA revelaram as preocupações dos idealizadores e dos pesquisadores dessas teorias com a formalização de conceitos, principalmente aqueles que são atribuídos à escola, denominados de conceitos científicos. Dessa maneira, eles propõem como necessidade social repensar a educação e, consequentemente, o processo de ensinar e aprender a Matemática.

No campo educacional, a apropriação dos conhecimentos científicos surge como um desafio para os profissionais envolvidos no processo de escolarização. Nessa perspectiva, Vygotsky (1987) ressalta a importância da mediação para o processo de escolarização dos indivíduos, pois "o aprendizado adequadamente organizado resulta em desenvolvimento mental e põe em movimento vários processos de desenvolvimento que, de outra forma, seriam impossíveis de acontecer" (p. 101).

Por conseguinte, apoiamo-nos no conceito de atividade proposto por Leontiev (1978, 1983) para melhor compreender a importância do trabalho docente na organização do ensino e sua efetiva contribuição para o desenvolvimento das funções psíquicas superiores dos estudantes, na relação mediada por instrumentos culturais entre os sujeitos com os objetos.

Moura et al. (2010) afirmam que a TA pode fundamentar o trabalho do professor na organização do ensino, pois envolve uma ação que deve estar voltada intencionalmente para a apropriação de conhecimentos produzidos historicamente, concretizando, assim, os objetivos sociais do currículo escolar. A organização do ensino é considerada pelos autores como atividade, porque implica que o professor defina ações que considerem as condições objetivas da escola; eleja instrumentos, processos de mediação dos sujeitos com os objetos; avalie o processo de ensino e aprendizagem, objetivos relacionados ao ensinar e aprender; e, por fim, constate a apropriação dos conhecimentos historicamente acumulados pelos discentes, relativos a sua necessidade e seu motivo. 
Com base nos pressupostos da TA, Moura (2010) desvela que a atividade de ensino do professor deve produzir e promover a atividade discente. Seu envolvimento com sua atividade ensino pode auxiliá-lo a tomar consciência de seu próprio trabalho e de seu objeto de ensino, e o produto da construção do saber será transformado em objeto de aprendizagem para os estudantes. Assim, na organização do ensino, o docente também exerce ações que promovem os conhecimentos teóricos em jogo, tornando-os objetos necessários a sua atividade de aprendizagem, o que simultaneamente cria no estudante a necessidade de apropriar-se do conceito em questão.

Para Lopes (2009), organizar o ensino assume importante papel na atividade docente, no que tange à aprendizagem, pois tanto o professor quanto os estudantes estarão mobilizados para apropriar-se de conhecimentos. Dessa forma, a Atividade Orientadora de Ensino (doravante, AOE) torna-se a unidade de formação entre professor e alunos, pois aquele, ao organizar o processo de ensinar, também qualifica seus conhecimentos (Moura, 1996, 2001).

Baseado no princípio histórico-cultural da atividade, Moura (2002) define o ensino como uma atividade que deve envolver o aluno num processo reflexivo, a partir da vivência de situações-problema que o levem a desenvolver significados próprios do conceito em jogo. Para Moura (2002), uma AOE pode ser definida como

aquela que se estrutura de modo a permitir que sujeitos interajam, mediados por um conteúdo, negociando significados, com o objetivo de solucionar coletivamente uma situação-problema. É atividade orientadora porque define elementos essenciais da ação educativa e respeita a dinâmica das interações que nem sempre chegam a resultados esperados pelo professor. Este estabelece os objetivos, define as ações e elege os instrumentos auxiliares de ensino, porém não detém todo o processo, justamente porque aceita que os sujeitos em interação partilhem significados que se modificam diante do objeto de conhecimento em discussão. (p. 155)

Logo, no coração da AOE encontra-se a situação problema como aspecto desencadeador da necessidade que levou o homem à construção de determinado conceito, promovendo o compartilhamento de significados e experiências entre os estudantes, num ambiente que, de forma coletiva, busca as soluções para a situação-problema e possibilita a troca e a produção de conhecimentos entre os envolvidos no dinâmico processo de ensino e aprendizagem. Assim, a AOE se configura por meio da intencionalidade do educador, ao articular instrumentos e estratégias que permitirão aos sujeitos produzir significados com o objeto de conhecimento (Moura, 1996).

Nessa perspectiva, Moura pontua três aspectos imprescindíveis para a estrutura da AOE: a síntese histórica do conceito, que possibilita ao professor apropriar-se do aspecto pedagógico da história do conceito (Moura, 1996, p. 20); a situação-problema ou a situação desencadeadora de aprendizagem, que deve contemplar a gênese do conceito e pode ser materializada de maneiras diferentes, com três recursos metodológicos para tal abordagem: os jogos, as situações que emergem do cotidiano e a história virtual do conceito (Moura, 2010, p. 103); e a síntese coletiva, que é a solução "matematicamente correta" da situação-problema desenvolvida pelos estudantes em coletividade (Cardoso et al., 2012, p. 4). 
Dessa maneira, este estudo centra-se na formação inicial de professores de Matemática, compreendendo a importância da problematização das ações pedagógicas do professor, uma vez que busca, por meio de situações de vivência e exploração de atividades de ensino, desenvolver as funções psíquicas dos estudantes, futuros professores de Matemática, acerca do estudo de Geometrias não Euclidianas como uma maneira de ampliar os conhecimentos no campo geométrico e, consequentemente, ressignificar o ensino de Geometria.

\section{Descrição do experimento realizado com os futuros professores de Matemática}

O trabalho foi desenvolvido com licenciandos em Matemática da Universidade do Estado da Bahia - UNEB/Campus X, localizada na cidade de Teixeira de Freitas, na Bahia. A priori, a proposta foi de cunho teórico-prático e teve a finalidade de construir, para o estudo, documentos que permitam analisar a produção de significados, por futuros professores de Matemática, a partir da vivência e exploração de Atividades de Ensino com diferentes modelos geométricos. Para tanto, foram utilizados os seguintes instrumentos de coleta de dados: questionário diagnóstico, Atividades de Ensino, gravações audiovisuais e roteiro de observação.

As Atividades de Ensino foram construídas a partir dos pressupostos teóricometodológicos da Atividade Orientadora de Ensino e utilizadas como contexto para estimular a negociação de significados de futuros professores de Matemática acerca do estudo de conceitos de Geometrias não Euclidianas. Os sistemas geométricos abordados tanto no questionário diagnóstico quanto nas Atividades de Ensino foram: Geometria Euclidiana, Geometria Esférica e Geometria Hiperbólica.

Os participantes foram divididos durante a pesquisa em quatro grupos com quatro integrantes cada e se autodenominaram: Beta, Delta, Geodésicos e Os Quatro Postulados. Para identificar os sujeitos no decorrer da pesquisa, utilizamos a seguinte codificação:

- LB 1, LB 2, LB 3, LB 4 (Licenciandos do grupo Beta);

- LD 1, LD 2, LD 3, LD 4 (Licenciandos do grupo Delta);

- LG 1, LG 2, LG 3, LG 4 (Licenciandos do grupo Geodésicos);

- LO 1, LO 2, LO 3, LO 4 (Licenciandos do grupo Os Quatro Postulados).

Para identificar, no processo de categorização, a origem dos dados desta pesquisa, denotamos a seguinte codificação: L (acompanhado da letra do grupo e o número) Licenciando e o grupo a que pertence; AE (acompanhado do número) - Atividade de Ensino; $\mathrm{PP}$ - Professor Pesquisador.

Atividades de Ensino 
DOI: $10.20396 /$ zet.v29i00.8661597

Tomando por base o referencial teórico adotado na pesquisa, foram planejadas e desenvolvidas seis Atividades de Ensino (AE) denominadas: AE 1 - O que diz Euclides?; AE 2 - Questionando Euclides?; AE 3 - A soma dos ângulos internos de um triângulo qualquer é sempre 180?; AE 4 - A Terra não é plana?; AE 5 - Outros espaços?; AE 6 - É uma questão de curvatura?. Essas AE foram constituídas por meio de adaptações de materiais produzidos por outros pesquisadores.

As AE serviram como fio condutor para construir um espaço de negociação de significados sobre diferentes modelos geométricos que se constituíram a partir de discussões, diálogos e reflexões produzidas pelos licenciandos e pelo professor-pesquisador. O processo de construção dos conhecimentos geométricos foi investigado pela necessidade de sua produção, analisando as limitações do modelo geométrico euclidiano para que emergissem novas formas de perceber e compreender o espaço em que vivemos.

Neste artigo iremos abordar a produção de significados dos licenciandos durante a aplicação da AE 2: Questionando Euclides? 


\section{ATIVIDADE 2 - QUESTIONANDO EUCLIDES?}

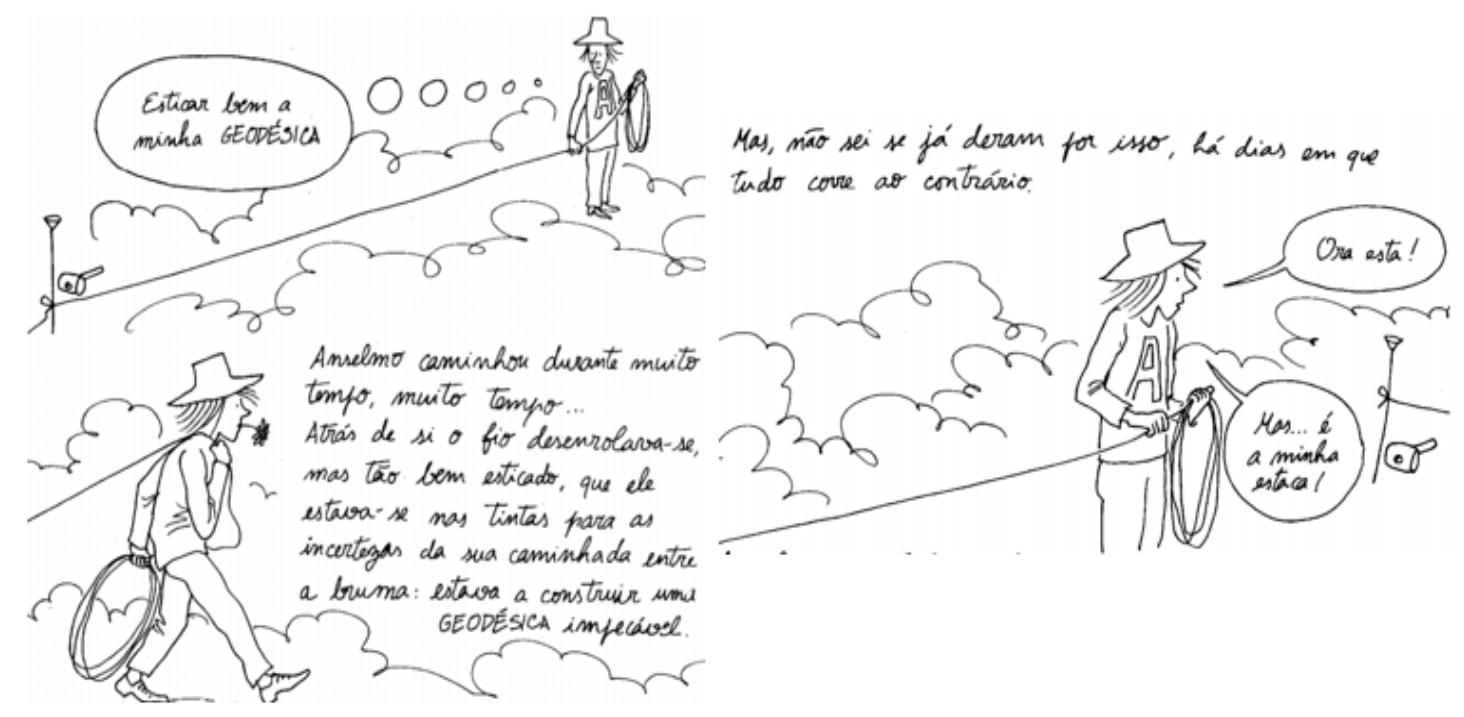

Figura: Material adaptado de "As aventuras de Anselmo curioso: os mistérios da Geometria"

Fonte: http://www.mat.uc.pt/ alma/escolas/alice/OS MISTERIOS DA GEOMETRIA.pdf

1. Se Anselmo saísse a partir da estaca e caminhasse $10 \mathrm{~km}$ ao sul. Depois virasse ao oeste e caminhasse por mais $10 \mathrm{~km}$. E virasse novamente e caminhasse $10 \mathrm{~km}$ ao Norte. É possivel Anselmo encontrar o ponto de partida? Justifique por meio de desenhos e/ou textos explicativo.

2. Imagine que Anselmo, resolveu sair a partir da estaca e caminhasse em linha reta infinitamente.

a) Desenhe o caminho percorrido por Anselmo numa folha de papel.

b) De acordo com o caminho desenhado na folha de papel, é possível Anselmo voltar ao ponto de partida?

c) Com fitas adesivas, represente o caminho percorrido por Anselmo na esfera de isopor? Que figura geométrica você encontrou? $O$ que você pode afirmar a partir dessa representação sobre o caminho percorrido por Anselmo?

d) Comparem as representações realizadas na folha de papel com as representações realizadas na bola de isopor e anote suas reflexões considerando suas relações. 
3. A partir das reflexões propostas até agora:

a) Marque um ponto sobre a esfera.

- Quantas "retas" vocês podem traçar passando por esse ponto?

- Na bola de isopor representem uma dessas retas.

b) O primeiro postulado de Euclides diz que por dois pontos pode passar apenas uma única reta.

- Esse postulado se verifica na superficie esférica? Porquê?

- Na superfície esférica as retas são infinitas e ilimitadas como na superfície plana?

c) Duas retas são chamadas concorrentes quando estão num mesmo plano e possuem um ponto em comum.

- Na superficie esférica existem retas concorrentes?

- Se existirem, na bola de isopor, represente duas retas concorrentes.

d) Duas retas são paralelas se estão num mesmo plano e não possuem nenhum ponto em comum na Geometria Euclidiana.

- Na superficie esférica existem retas paralelas?

- Se existirem, na bola de isopor, represente essa ideia.

e) Sejam X e Y dois pontos distintos. Em quantas partes eles dividem:

a) uma reta euclidiana?

b) uma reta esférica?

\section{REFERÊNCIAS:}

NASCIMENTO, Anna Karla Silva do. Geometrias não-euclidianas como anomalias: implicações para o ensino de geometria e medidas. Dissertação (Mestrado) - Universidade Federal do Rio Grande do Norte. Pós-Graduação em Ensino de Ciências Naturais e Matemática. Natal, 2013.

PETIT, Jean-Pierre. As Aventuras de Anselmo Curioso - Os Mistérios da Geometria, traduzido por Luís Pignatelli, Lisboa: Publicações Dom Quixote, 1982.

PRESTES, Irene da Conceição Rodrigues. Geometria esférica: uma conexão com a geografia.201 f. Dissertação (Mestrado em Educação) - Pontificia Universidade Católica de São Paulo, São Paulo: 2006. Disponível em: https://tede2.pucsp.br/handle/handle/11101. Acessado em: 18/07/2018.

Figura 1 - AE 2: Questionando Euclides?

Fonte: o próprio autor (2018)

Aspectos constitutivos da produção de significados geométricos sobre o estudo de diferentes Geometrias

A partir da leitura cuidadosa e aprofundada do material das observações, do registro escrito produzido pelos participantes e das transcrições dos eventos ocorridos nos encontros, agrupamos as informações por meio de conteúdos semelhantes, complementares ou contradição, de maneira a apreender a produção de significados dos futuros professores de Matemática sobre conceitos fundamentais das Geometrias Não Euclidianas.

A triangulação dos dados fez emergir as seguintes categorias de análise: Conflito - da validade lógica à validade empírica e Ruptura - do espaço euclidiano para outros espaços.

A categoria "Conflito - da validade lógica à validade empírica" se manifesta primeiramente no conhecimento prévio do participante, quando esse assume a Geometria 
Euclidiana como um sistema logicamente consistente, considerando-o como a única forma de interpretar e representar o espaço físico real. E se completa quando o participante compreende que a validade empírica do conhecimento geométrico euclidiano depende do contexto em que é utilizado.

Já a categoria "Ruptura - do espaço euclidiano para outros espaços" se revela quando há o rompimento do paradigma de uma única Geometria, ou seja, na aceitação de modelos geométricos não euclidianos e no movimento de construção de novos conhecimentos a partir dessa compreensão.

A seguir apresentaremos o processo de análise da produção de significados dos participantes da pesquisa a partir das categorias propostas para esse fim.

\section{Produção de Significados da AE 2: questionando Euclides?}

Este Episódio é o recorte do terceiro encontro da aplicação da proposta de intervenção que aconteceu no dia 04 de maio de 2019. O episódio tem sua estrutura captada no momento da plenária da $\mathrm{AE} 2$, e destacamos o movimento dos licenciandos para formalizar o conceito de retas paralelas e retas coincidentes tanto na Geometria Euclidiana quanto na Geometria Esférica.

No Episódio, destacamos o movimento dos licenciandos durante a discussão acerca da construção do conceito de paralelismo entre retas em uma superfície esférica a partir do uso de material manipulativo. Assim, cada grupo recebeu um kit contendo os seguintes materiais: bola de isopor, fitas adesivas de cores diferentes, tesoura, canetas coloridas, borrachinha de dinheiro (elástico), régua e alfinetes.

Cena 1: Discussão acerca do paralelismo entre retas na superfície esférica

PP: Duas retas são paralelas se estão no mesmo plano e não possuem nenhum ponto em comum. Na superfície esférica existe retas paralelas?

LB 3: Então... Nosso grupo foi uma briga danada (risos). Mas a gente mediu certinho; a distância entre as retas foi de 2,5 cm, mas não com circunferências máximas.

LB 4: A gente consegue fazer várias retas paralelas, só que com circunferências menores.

LB 3: Mas elas terão a mesma distância entre elas. Logo, existe!

LO 4: A gente também discutiu bastante... A nossa dúvida inicialmente era referente a retas coincidentes, se retas coincidentes eram paralelas. Porque na geometria esférica, a reta ou geodésica, ela só é se ela passa pela circunferência maior. Então, se for ter retas coincidentes, você tem retas paralelas. Porém a gente definiu que retas coincidentes não são paralelas, para a nossa discussão aqui não existe retas paralelas na esférica.

$L B$ 3: Não entendi ainda. Por que na esférica as retas coincidentes não seriam paralelas?

LO 4: As retas coincidentes não são paralelas nem na Geometria Plana.

LB 3: Mas a gente considera paralela as retas coincidentes porque tem a mesma distância. A distância é zero! Se a distância é zero, elas são paralelas. Porque... porque fala que, dado dois pontos, os pontos precisam ter a mesma distância.

(Diálogo entre participantes, 2019)

Na discussão presente na Cena 1, observamos que o grupo LB propõe a existência de paralelismo entre retas na Geometria Esférica, relacionando esse conceito com a ideia de 
DOI: $10.20396 /$ zet.v29i00.8661597

distância entre as retas, ou seja, tem-se paralelismo entre retas quando a distância entre os pontos de uma reta a outra for da mesma medida sucessivamente, como sugere LB 3: "Então... Nosso grupo foi uma briga danada (risos). Mas a gente mediu certinho; a distância entre as retas foi de 2,5 cm mas não com circunferências máximas." (LB 3, Cena 1, 2019).

Na Figura 2, apresentamos a construção, realizada pelo grupo LB, de retas paralelas na bola de isopor para justificar a existência desse conceito na Geometria Esférica.

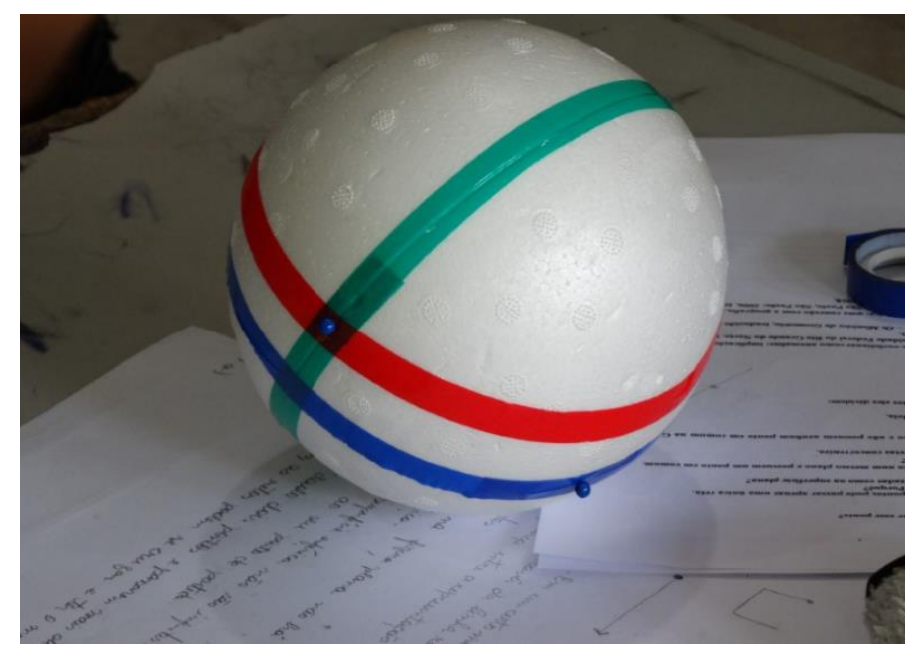

Figura 2 - Construção de retas paralelas na bola de isopor

Fonte: Dados da pesquisa (04/05/2019)

A representação proposta pelo grupo LB na Figura 2 sugere que as fitas azul e vermelha representam duas geodésicas que são paralelas por manterem uma distância de 2,5 $\mathrm{cm}$ entre elas no transcorrer de suas finitudes. Observamos que o grupo LB procura dar coerência ao conceito de paralelismo na superfície esférica a partir de uma das consequências do Postulado das Paralelas de Euclides, que sugere a existência de um par de retas equidistantes. Nesse contexto, analisamos que há uma ruptura, pelos participantes, em relação à existência de um único modelo geométrico, pois aceitaram a ideia de paralelismo na superfície esférica e atribuem significados para esse novo conceito, considerando apenas a equidistância entre retas como juízo de valor para a formalização desse conceito.

A ideia construída pelo grupo LB é refutada pela participante LO 4, quando sinaliza que "na Geometria Esférica, a reta ou geodésica, ela só é se ela passa pela circunferência maior" (LO 4, Cena 1, 2019), o que evidencia um erro conceitual cometido pelo grupo LB, ao propor que existe paralelismo na superfície esférica, porque admitem que a fita vermelha denota uma geodésica na representação exposta na Figura 2. Em nossa análise, a participante LO 4, com a aceitação do modelo esférico, não só rompe com a ideia de um único modelo geométrico como transcende o conceito de paralelismo, ao internalizar o conceito de geodésica em uma superfície esférica. Produzindo novos significados, torna-os capazes de questionar a existência de paralelismo na superfície esférica, ao dizer: 
Porque na geometria esférica, a reta ou geodésica, ela só é se ela passa pela circunferência maior. Então, se for ter retas coincidentes, você tem retas paralelas. Porém a gente definiu que retas coincidentes não são paralelas, para a nossa discussão aqui não existe retas paralelas na esférica. (LO 4, Cena 1, 2019)

O movimento realizado pelos participantes no Episódio 3 se manifestou no primeiro momento por meio da ruptura do paradigma da existência de um modelo geométrico único, capaz de representar a realidade física em sua totalidade. Assim, os participantes, ao constatarem algumas limitações no modelo geométrico euclidiano para modelar as diversas situações que emergem numa superfície não plana, passaram a atribuir novos significados para o conceito de paralelismo, o que revela que o conhecimento geométrico não se apresenta mais como algo pronto e acabado, mas, sim, como algo vivo e passivo de ser construído e/ou reconstruído.

As categorias de análise de produção de significados dos participantes emergem em um processo espiralado, por meio de revoluções, em que a internalização dos conceitos pode ser captada por meio do conflito entre a consistência lógica da Geometria Euclidiana e sua aplicação empírica, podendo conduzir ou não à ruptura do paradigma de um único modelo geométrico. Ressaltamos também que a produção de significados dos participantes foi captada e representada em nossa pesquisa por meio de um processo em espiral, em que a ordem das categorias não emerge de maneira fixa e predefinida, e a ruptura pode conduzir ao surgimento de novos conflitos e vice-versa.

Dito isso, compreendemos que os participantes, ao romperem com a ideia de uma única geometria do real ao longo do processo interativo apresentado na Cena 1, foram refinando seu processo de pensamento e tomando decisões que os levaram a afirmar corretamente que na Geometria Esférica não existe paralelismo entre geodésicas. Essa afirmação foi proposta pelo grupo LO, que condicionou a existência de paralelismo entre geodésicas na superfície esférica, ao propor como verdadeira a premissa de que retas coincidentes não se constituem em retas paralelas.

No diálogo apresentado pelos participantes na Cena 1, observamos que a premissa proposta por LO 4: "As retas coincidentes não são paralelas nem na Geometria Plana" (LO 4, Cena 1, 2019) gerou uma espécie de conflito para os participantes que defendiam a existência de paralelismo entre geodésicas na superfície esférica. A participante LB 3 confronta os dizeres de LO 4, ao propor: "Mas a gente considera paralela as retas coincidentes porque tem a mesma distância. A distância é zero! Se a distância é zero elas são paralelas. Porque... porque fala que dado dois pontos os pontos precisam ter a mesma distância" (LB 3, Cena 1, 2019).

Em nossa análise, os dizeres da participante LB 3 expressam que os participantes desse grupo atribuem significados para o paralelismo entre retas na Geometria Euclidiana, considerando a equidistância entre os pontos pertencentes às retas como o único aspecto necessário para determinar o paralelismo entre retas. Assim, compreendemos que os integrantes do grupo LB não internalizaram o conceito de paralelismo entre retas a partir do entendimento do Postulado das Paralelas aceito atualmente para a geometria euclidiana - 
DOI: $10.20396 /$ zet.v29i00.8661597

dado uma reta e um ponto fora dela existe apenas uma única reta paralela à reta dada , mas, sim, a partir de uma das consequências impostas pelo Postulado das Paralelas, que resulta na equidistância entre retas.

Nesse contexto, atribuímos as dificuldades dos participantes em verificar a existência de paralelismo na Geometria Esférica ao fato de não terem internalizado o conceito de paralelismo na Geometria Euclidiana, e a formação deficitária desse conhecimento contribuiu para a consolidação de um erro conceitual, quando propõem que retas coincidentes são retas paralelas.

$\mathrm{Na}$ Cena 2, destacamos a atribuição de significados dos participantes para retas coincidentes a partir da aceitação de que há paralelismo entre essas retas coincidentes. A ideia de retas coincidentes, atrelada ao conceito de paralelismo, é aos poucos descontruída pelos participantes, no momento em que recorrem ao Postulado das Paralelas como proposto por Playfair e utilizado atualmente - dado uma reta e um ponto fora dela, pode-se traçar por este ponto uma única reta paralela à reta dada.

Cena 2: Discussão acerca do paralelismo a partir do Postulado das Paralelas

PP: Então, vamos lá para o V postulado de Euclides.

LO 3: Mas são duas condições para serem paralelas.

LO 4: Isso que causou uma confusão em minha cabeça, porque retas coincidentes eram paralelas. Mas, pela definição, retas paralelas não podem ter pontos em comum, e se elas são coincidentes, elas têm todos os pontos em comum.

PP: Vamos lá, então! O V postulado que a gente trabalha hoje na educação básica, que é uma transformação do postulado de Euclides, uma das ideias é que, dado uma reta e um ponto fora desta reta, pode-se traçar uma única reta paralela à reta dada. Então, você tem que ter, de certa forma, um ponto fora dessa reta.

LB 3: Ohhh! É ... porque eu aprendi desse jeito. No meu curso todo e até nos minicursos que eu fiz, a gente aprendeu que retas coincidentes são retas paralelas.

LB 2: Estou com o pensamento da $\mathrm{LO} 4$, as retas não podem ter pontos em comum... Se forem em comum, já elimina a chance de ser paralelas.

(Diálogo entre participantes, 2019)

Na Cena 2, observamos o movimento da participante LO 4 para descontruir a ideia de que retas coincidentes são retas paralelas. A participante assume o conflito como um caminho para questionar algo que lhe parecia verdadeiro e definido, ao dizer: "Isso que causou uma confusão em minha cabeça porque retas coincidentes eram paralelas" (LO 4, Cena 2, 2019). Nos dizeres da participante LB 3, encontramos indícios de que esse erro conceitual foi propagado durante o curso superior: "É ... porque eu aprendi desse jeito. No meu curso todo e até nos minicursos que eu fiz a gente aprendeu que retas coincidentes são retas paralelas" (LB 3, Cena 2, 2019). Nesse contexto, compreendemos que os participantes se apropriaram de maneira equivocada do conceito de paralelismo entre retas e que os estudos realizados durante o curso de Licenciatura em Matemática não foram suficientes para compreender a dimensão conceitual que envolve a ideia de paralelismo.

O movimento dos participantes para a construção do conceito de paralelismo na superfície esférica motivou os licenciandos a repensarem o conceito de paralelismo na Geometria Euclidiana, na qual a existência de paralelismo na Geometria é algo aceito e 
DOI: $10.20396 /$ zet.v29i00.8661597

consolidado. A aceitação desse conceito pelos participantes os conduziu a buscar pelo menos um caso particular para validar a ideia de paralelismo, considerando a existência desse conceito independentemente do tipo de superfície em estudo.

\section{Considerações finais}

Compreendemos que as manifestações presentes no episódio indicam que os sujeitos participantes da pesquisa desconhecem modelos geométricos diferentes do euclidiano, reconhecendo a Geometria Euclidiana como a única maneira para descrever e interpretar o espaço físico em que vivem. Além disso, constatamos que os licenciandos, ao aceitarem a existência de outros modelos geométricos, modificam a maneira como se relacionam com o espaço em que vivem e, assim, desenvolvem maior autonomia no processo de construção dos conceitos geométricos em estudo.

Ao estudarem o conceito de paralelismo na superfície esférica, os estudantes romperam com a consistência lógica do modelo geométrico euclidiano, quando verificaram que não existe paralelismo entre geodésicas na Geometria Esférica. Assim, passaram a atribuir novos significados para o conceito de paralelismo na Geometria Euclidiana, ao compreenderem que retas coincidentes não podem ser consideradas retas paralelas.

Por fim, acreditamos que, dentre as contribuições desta investigação, está a reflexão acerca da formação de futuros professores de Matemática, no que diz respeito à apropriação de conhecimentos geométricos não euclidianos como uma possibilidade para modificar o modo como os professores entendem e realizam a prática de ensino de Geometria.

\section{Referências}

Abreu, G. (2000). O papel mediador da cultura na aprendizagem da matemática: a perspectiva de Vygotsky. Educação, Sociedade \& Culturas, (13), 105-117.

Asbahr, F. S. F. (2014). Sentido pessoal, significado social e atividade de estudo: uma revisão teórica. Revista Quadrimestral da Associação Brasileira de Psicologia Escolar e Educacional, 18(2), 265-272. DOI: https://doi.org/10.1590/2175-3539/2014/0182744

Braida, F. C. (2012). Interferência do enquadramento de trabalho nas representações sobre o ensino de leitura no contexto da formação inicial docente sob o entendimento da Teoria Holística da Atividade. Tese de Doutorado em Letras - Estudos Linguísticos. Santa Maria, RS: Universidade Federal de Santa Maria.

Cardoso, N. P., Hundertmarck, J., Perlin, P., \& Lopes, A. R. L. V. (2012). Atividade Orientadora de Ensino: uma experiência utilizando trocas nos anos iniciais. In Anais da $3^{a}$ Escola de Inverno de Educação Matemática (pp. 1-11). Santa Maria, RS: $1^{\circ}$ Encontro Nacional PIBID-MATEMÁTICA. Recuperado de https://www.ufsm.br/app/uploads/sites/534/2020/03/RE_Cardoso_Naise.pdf

Castorina, J. A. (1996). O debate Piaget-Vigotsky: a busca de um critério para uma avaliação. In J. A. Castorina, E. Ferreiro, D. Lerner \& M. K. Oliveira. Piaget - Vigotsky: novas contribuições para o debate (pp. 7-50). São Paulo: Ática. 
DOI: $10.20396 /$ zet.v29i00.8661597

Duarte, N. (2004). Formação do indivíduo, consciência e alienação: o ser humano na psicologia de A. N. Leontiev. Caderno CEDES, 24(62), 44-63. Disponível em: http://www.scielo.br/ pdf/ccedes/v24n62/20091.pdf

Leontiev, A. N. (1978). O desenvolvimento do psiquismo (2a ed.). São Paulo: Centauro.

Lopes, A. R. L. V. (2009). Aprendizagem da docência em matemática: o Clube de Matemática como espaço de formação inicial de professores. Passo Fundo: Ed. Universidade de Passo Fundo.

Moura, M. O., Araújo, E. S., Ribeiro, F. D., Panossian, M. L., \& Moretti, V. D. (2010). A atividade orientadora de ensino como unidade entre o ensino e a aprendizagem. In M. O. Moura (Org.), A atividade pedagógica na teoria histórico-cultural (pp. 81-109). Brasília, DF: Liber Livro.

Moura, M. O. (1996). Controle da variação de quantidades: atividades de ensino. São Paulo: FEUSP.

Moura, M. O. (2001). A atividade de ensino como ação formadora. In A. D. Castro \& A. M. P. Carvalho (Orgs.), Ensinar a ensinar: didática para a escola fundamental e média (143-162). São Paulo: Thomson Learning.

Moysés, L. (1997). Aplicações de Vygotsky à educação matemática. Campinas: Papirus.

Vygotsky, L. S. (1987). Pensamento e linguagem. São Paulo: Martins Fontes.

Vygotsky, L. S. (1993). Pensamiento y palabra. In L. S. Vygotsky, Obras escogidas (vol. 2) (pp. 287-348). Madrid: Visor.

Vygotsky, L. S. (2003). A formação social da mente: desenvolvimento da percepção e da atenção (6a ed.). São Paulo: Martins Fontes.

Vygotsky, L. S., Luria, A. R., \& Leontiev, A. N. (2010). Linguagem, desenvolvimento e aprendizagem (11a ed.). São Paulo: Ícone. 